\title{
Co-disposal of waste rock with backfill
}

\author{
C Lee Golder Associates Ltd., Canada \\ F Gu Golder Associates Ltd., Canada
}

\begin{abstract}
Most underground mines produce a significant quantity of development waste rock in order to access the orebody and provide underground excavations for mining infrastructure. Much of this development waste rock is hauled to surface in many mines and results in a substantial operating cost. In addition, most mines use cemented backfill to fill the stope voids that are not filled with waste rock, and this cemented backfill represents a substantial operating cost as well. Some mines do dispose of some development waste rock in stopes, however, the operational difficulties associated with disposing of a large quantity of rock in the stopes prevents many mines from taking advantage of this option.

One of the principal difficulties is the placement of backfill and waste rock in the right proportions so that there are no areas of waste rock only, i.e. rock that has no binding matrix to hold the rock particles together. Traditional methods of waste rock disposal in backfill stopes using scoops that dump their buckets over the brow have been severely limited by this constraint and resulted in limitations on the rate of waste rock delivery into the stope, as well as the maximum amount of rock that can be placed into the stope. Delivery of waste rock from the development face to the stope can also be challenging if the distance is substantial. Scheduling of the development waste rock disposal in the available stopes can be difficult since the options for waste rock storage are typically limited on an active mining level and the peaks in development rock production may exceed the capacity of a stope to receive development waste rock.
\end{abstract}

This paper is an adaptation of a previous paper prepared for the 20th International Seminar on Paste and Thickened Tailings, held in June 2017 in Beijing, and discusses procedures, methods and equipment that can be used to allow waste rock to be delivered more effectively to the stopes to lower a mine's operating costs.

Keywords: backfill, waste rock, slinger, co-disposal, paste fill

\section{Introduction}

The disposal of development waste rock into stopes has a large impact on mining costs due to a reduction in waste hauled to surface and a reduction in the costs of backfilling. To assess the opportunity for improvement in mine economics by disposing of waste rock with the backfill, the cost of the backfill and the cost of the waste rock haulage must be known. A simplified calculation of the impact of disposing of waste rock underground is shown in Table 1.

As described in Table 1, the potential savings in mining costs per tonne of waste rock is CAD 16.00 per tonne of waste rock (assuming that waste rock and backfill dry densities are similar).

Since mining costs are calculated in CAD/tonne of ore, the impact of this savings on the mining costs also depends on the waste rock to ore ratio, and for a 1:4 waste/ore ratio the total savings per tonne of ore would be CAD 4.00 per tonne in this example. For a one million tonne per annum mining rate, this reduction in mining costs is equivalent to a CAD 4 million savings in yearly operating costs. This cost is directly proportional to the amount of waste rock mined so that larger operations can contemplate savings in the 10 s of millions of dollars per year.

This paper was originally published in the Proceedings of the 20th International Seminar on Paste and Thickened Tailings. Acknowledgement is given to the University of Science and Technology Beijing for their permission to republish this paper. 
Table 1 Mining cost savings per tonne of waste rock produced (simplified theoretical example)

\begin{tabular}{lll}
\hline Cost of waste rock hoisting & CAD 2.00 & per tonne \\
Cost of haulage to dump & CAD 2.50 & per tonne \\
Cost of waste dump placement & CAD 1.50 & per tonne \\
Total waste rock disposal & CAD 6.00 & per tonne \\
Cost of paste backfill & CAD 10.00 & per tonne* \\
Total differential & CAD 16.00 & per tonne** \\
\hline
\end{tabular}

*Per tonne of backfill (dry solids) that could be displaced by a tonne of waste rock.

**Per tonne of waste rock (dry solids) disposed of in-stope.

There are other factors that contribute to the cost savings such as tailings disposal costs, differential costs for hauling waste underground to the material handling circuit versus disposal in the stopes, traffic and ventilation considerations, etc. All these costs should be added into the equation to determine the net reduction in capital and operating costs.

In addition to the potential savings in operating costs, the removal of waste rock haulage from the materials handling system may allow some mines to mine more ore. This is especially true of shaft mines where there is no potential for adding more trucks or improving traffic management in order to increase haulage tonnages. The potential increase in revenue due to mining more ore with the same fixed costs is substantial and makes co-disposal of waste rock for haulage-limited operations a major improvement.

\section{$2 \quad$ Previous attempts at waste rock co-disposal}

Many mines around the world have, to some degree implemented waste rock co-disposal into their mining method. Sometimes it is as simple as disposing of waste rock in secondary stopes where there is no requirement for fill strength. In other cases, effort has been made to co-dispose of waste rock in conjunction with cemented backfill with varying levels of effort and success.

Kuganathan \& Sheppard (2001) describe the co-disposal of a cemented hydraulic fill slurry with graded rockfill at Mount Isa Mine. The combination of these two constituents yielded a homogenous fill that was not prone to segregation in the way the cemented rockfill was prone. The major disadvantage of that system was the cost of the capital equipment (conveyors, etc.) to distribute the waste rock to the stopes.

Mount Isa also used the 'Christmas Tree' co-disposal method where uncemented rock was placed through a borehole into the centre of a stope, and cemented flowable fill (either paste or hydraulic fill) was placed around the cones of deposited rock. The uncemented waste rock was encapsulated in the cemented fill and served to fill the void while avoiding an uncemented wall at the edges of the stope that would be exposed upon extraction of the adjacent stope. This method allowed disposal of waste rock, however, it is not as beneficial for other mines with smaller stopes where the cost of fill passes to the centre of the stope and the limited amount of rock that can be discharged into the stope (while maintaining a suitable barrier layer of cemented fill) makes the option less attractive.

Many mines also discharge scoop buckets over the brow of longhole stopes at a rate that is usually set to ensure that the uncemented rock is falling into a bed of uncured fill and is able to embed itself in the fill to some extent. This option is limited in terms of the amount of rock that can be safely discharged into the stope without creating pockets of uncemented fill that could result in dilution into the adjacent stope.

Almost all mines discharge waste rock into captive secondary stopes where no free faces will be exposed. This represents a good opportunity for waste rock disposal without issues around backfill dilution. However, the disposal of waste rock into secondary stopes typically only displaces low-strength fill, whereas waste rock disposal into primary stopes displaces higher strength, more expensive fill. 
In summary, waste rock disposal in underground stopes is a widespread practice, however, no operation, to Golders' knowledge, has published the perfect solution to maximise the potential of the waste rock.

\section{The ideal characteristics of waste rock co-disposal}

To determine the best solution for waste rock co-disposal it is really necessary to set the criteria for what constitutes an ideal co-disposal system. Once those ideal criteria are set, the next step is to determine if any equipment or procedures can be applied to meet those criteria.

The ideal waste rock disposal criteria are:

- Dispose of waste rock in high-strength, primary stopes where the cost of backfill is the highest.

- Maintain or increase the strength of the overall cemented fill mass by incorporating waste rock.

- Eliminate material handling costs to transport waste rock to surface.

- Minimise operational effort to incorporate waste rock into the cemented fill, i.e. no significant amounts of extra equipment, no crushing, rehandling, etc.

- Allow the co-disposal of waste rock at all times, i.e. dispose of waste rock as it is produced so that no storage or rehandling is required.

\subsection{Disposal of waste rock in primary stopes}

As discussed previously in the review of current practices for waste rock co-disposal, there are many mines that dispose of some waste rock in primary stopes, but all of those efforts, to the authors' knowledge, are incomplete solutions to the problem and result in only a small fraction of the waste rock being disposed of in the stope.

To allow disposal of waste rock throughout the stope, it is considered likely that the waste rock and a cemented fill product must be mixed and then distributed around the stope so that larger particles are not prone to segregation.

This is practically difficult since methods of moving rock (truck, conveyors, raises) are different than moving paste fill or hydraulic fill (pipelines). In addition, neither rock or paste transportation systems are amenable to distributing the material evenly around the stope since they generally discharge from a single location.

\subsection{Maintaining or increasing the fill strength}

Since the objective of backfill is to maximise the ore recovery at the lowest possible backfill cost, it is desirable to have a broad distribution of particle sizes with the finer particles binding the larger particles together.

The concrete industry has optimised the gradation requirements for small-particle cemented mixtures (usually less than $75 \mathrm{~mm}$ top size particle). This is primarily due to the limitations on larger particle sizes since larger particles can have localised detrimental impact for smaller pours, and concrete is relied upon to be homogenous and uniform. However, for larger fill masses, such as in backfilled stopes, the use of larger particles is more attractive because the impact of larger particles on localised fill areas is not important given the lower standards required for backfill failure and dilution versus concrete where no concrete is expected to fail. For concrete, the Talbot curve illustrates the ideal gradation required to maximise strengths (Figure 1). 


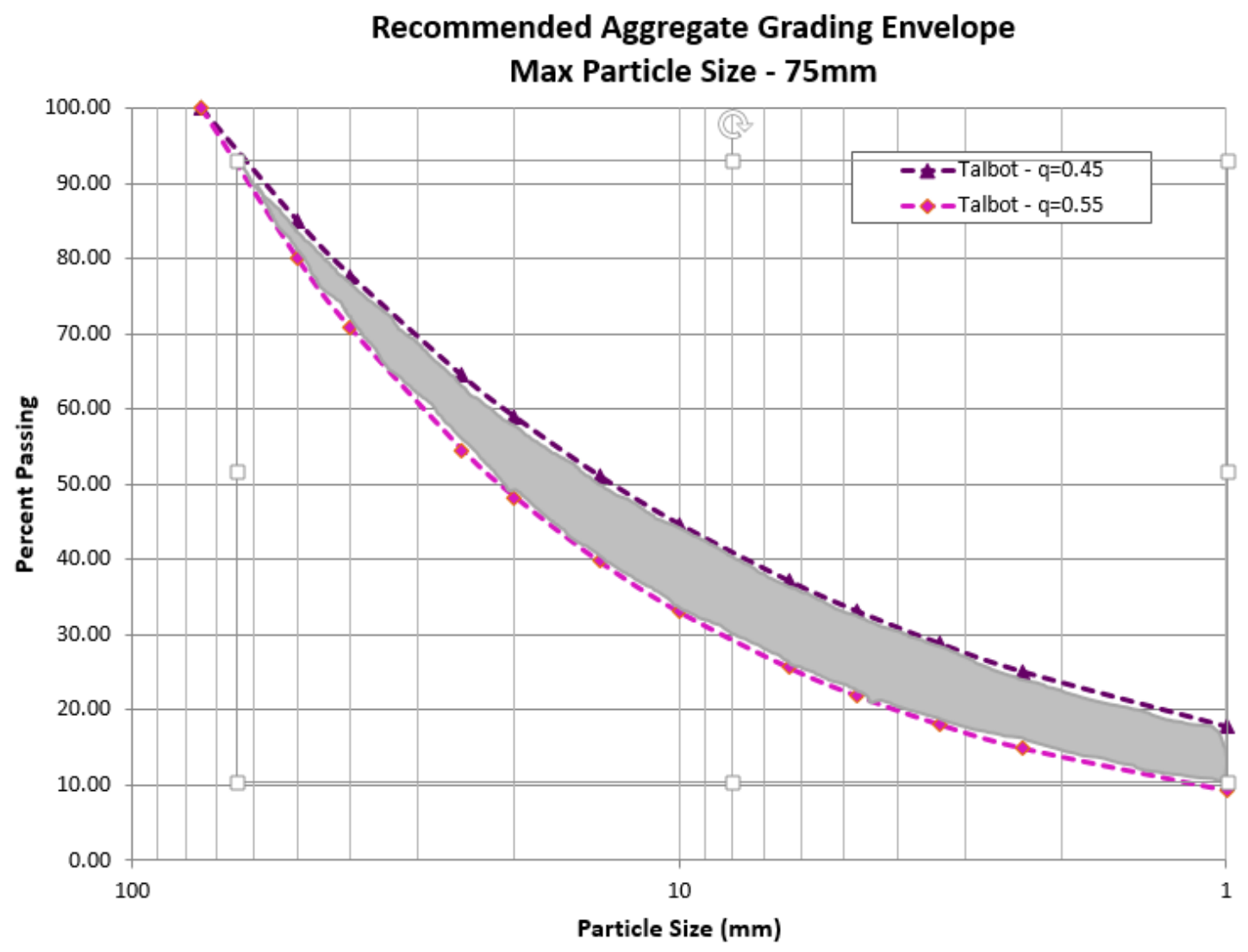

Figure 1 Talbot curve

For backfill, the Talbot curve can be extrapolated to larger particles to achieve the required strengths with a minimum of cement addition. The addition of large particles in the development waste rock essentially removes an equivalent amount of cemented fines matrix. As long as the ratio of cemented fines to coarser rock is not too low, all the spaces between the coarse particles will be filled with cemented material and all the coarse particles fill a space without any cement required to achieve a much higher strength than the cemented fines material. From this description, it may appear that the strength of the overall fill mass will be the strength of the cemented matrix, and if the target strength is met with a cemented paste fill content of $5 \%$ cement content, then a 50/50 mixture of paste fill and rock would require only $2.5 \%$ cement content to achieve the same target strength as the $5 \%$ cement content paste fill.

However, there is an additional mechanical strength gain associated with the coarse particle to coarse particle interlocking that begins to increase strengths beyond the strength of the fine cemented matrix. This strength increase is dependent on the strength of the rock since the point-to-point contact between coarse rock particles impart a large load over a small area.

Theoretically, this indicates that for the stated 50/50 mixture of paste fill and rock, a cement content of $2.5 \%$ will likely result in a higher strength than a $100 \%$ paste fill recipe with $5 \%$ cement content.

The mechanical interlocking of the rock also contributes to different stiffness properties of the fill mass and, whereas the $100 \%$ paste recipe stiffness or Young's modulus may be low, the addition of sufficient quantities of waste rock will increase the backfill stiffness. This may be of benefit when fill strength requirements include a minimum stiffness requirement to prevent hanging wall closure and/or distribution of stresses to the outer limits of the orebody, in the case of large orebodies that are completely extracted without leaving any rock pillars. 


\subsection{Eliminate material handling costs to transport rock to surface}

The cost to transport rock to surface is highly dependent on the mine's material handling system, location of waste rock dump and properties of the waste rock.

Deep mines with multiple shafts have the most to gain from a reduction in waste haulage. Shallower ramp haulage mines also have much to gain as they extend deeper since the haulage cost goes up substantially with depth.

Mines that have geochemically problematic waste rock with acid rock drainage (ARD) or other environmental concerns will have additional costs associated with waste dump construction, operation and closure.

Long travel distances from the mine access to the waste dump also increase the material handling costs.

Although the handling of waste rock cannot be completely eliminated when disposing of waste in the stopes, the waste rock handling cost is considerably less than haulage to surface.

\subsection{Minimise effort to incorporate the waste rock into the fill}

Many of the previous attempts to incorporate waste rock into fill have relied upon a crushed waste rock product, long delivery conveyors, raises and other infrastructure. It is most desirable to use the waste rock as is, without any further particle size sorting or modification. In addition, it is desirable to be able to move the waste rock into the stope with minimal effort.

The least amount of effort to incorporate waste rock occurs when the development is near to the deposition point and ideally on the same working level. Some equipment will be required to incorporate the waste rock into the fill and will be discussed in later sections.

\subsection{Allow the co-disposal of waste rock at all times}

Although this goal is impossible to achieve at all times, it is possible to partly achieve this goal. The initial development of the mine will require waste rock to be removed, but as soon as the first stope is ready for backfill, there is the opportunity to dispose of waste rock.

Co-disposal of waste rock would need to be another part of the mine scheduling if it were to be optimised. This is potentially a major impediment to the concept of using waste rock underground because it is another 'optional' task which may be passed over in order to achieve core objectives such as tonnes of ore mined, etc.

The added complexity of scheduling development and waste rock filling to occur at certain times will require more attention, however, if the potential cost savings are adequately high, it is worth the extra effort. As with all new initiatives that mine operators are not familiar with, there will need to be leadership and commitment to making the co-disposal of waste rock a normal part of the mining cycle.

For example, the limitation to waste rock co-disposal may be as simple as the availability of equipment to handle the waste rock into the stope if there is a conflicting need for that same equipment for production.

If the mindset is that co-disposal is optional, it is likely that it will be frequently overshadowed by production. For co-disposal to work, the evaluation of mine operations performance must be linked to co-disposal rather than just production of ore.

\section{$4 \quad$ Waste rock co-disposal solution}

Given the potential benefits of waste rock co-disposal and the ideal design criteria described in the previous sections, Golder has worked with Conveyor Application Systems (CAS) to develop a potential solution that satisfies the ideal criteria.

The concept is based on CAS's self-propelled slinger vehicle shown in Figures 2 and 3 which has been used in many mining applications for the distribution of stemming material, aggregate and concrete. The slinger receives material into a hopper and then meters that material out of the hopper and into a high-speed slinger 
conveyor which throws the material in a direction that is controlled by the slinger. The tilt angle of the slinger and the slinger speed can be modified so that the direction, distance of throw and trajectory are also modifiable.

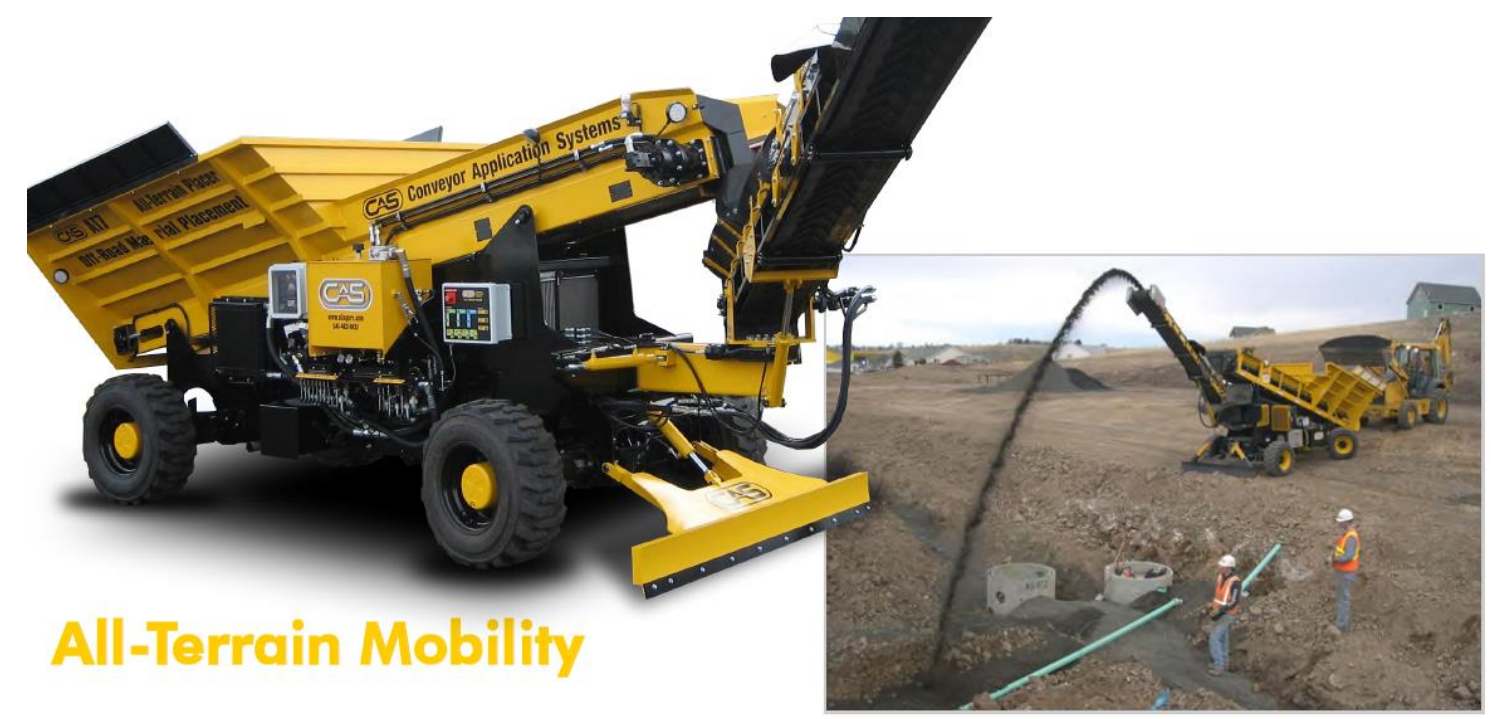

Figure 2 CAS slinger

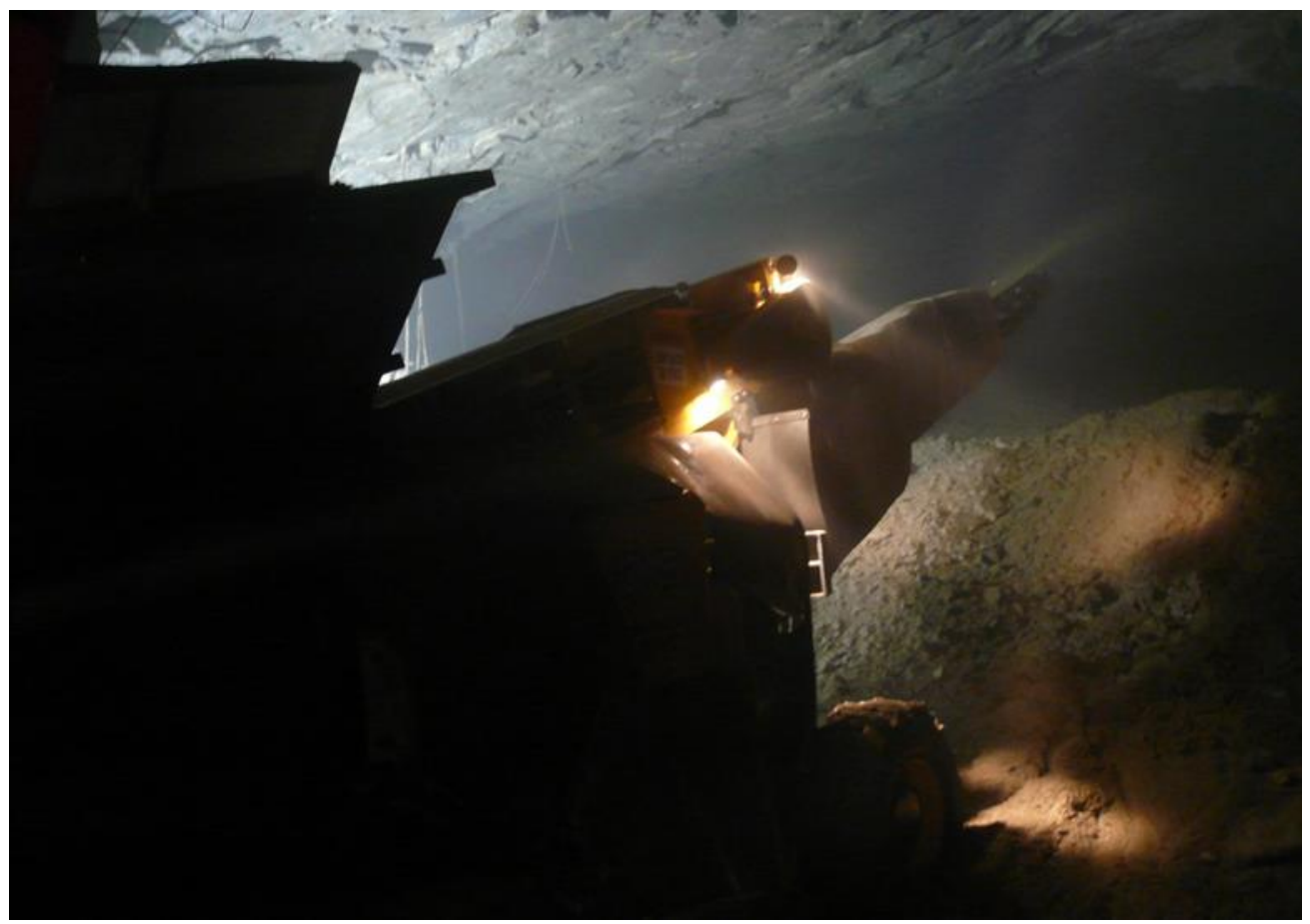

Figure 3 Filling voids underground

Although this equipment fits most of the needs of an underground co-disposal system, there are some areas where the equipment can be improved in order to function better for the specific needs of the mine environment. The areas that needed to be addressed were identified as:

- Must be able to accommodate large rocks up to $300 \mathrm{~mm}$ in size.

- Must have grizzly to reject rocks that are larger than $300 \mathrm{~mm}$ and allow rehandling.

- Must have the ability to blend the rock and paste prior to discharging both into the stope.

- Must be robust and suitable for the underground mine environment.

- Must be towable by scoop or service vehicle. 
Based on this list of required features, CAS has performed some preliminary design on a prototype machine that would fit the requirements of underground waste rock co-disposal.

Screenshots of the design are shown in Figures 4, 5 and 6.

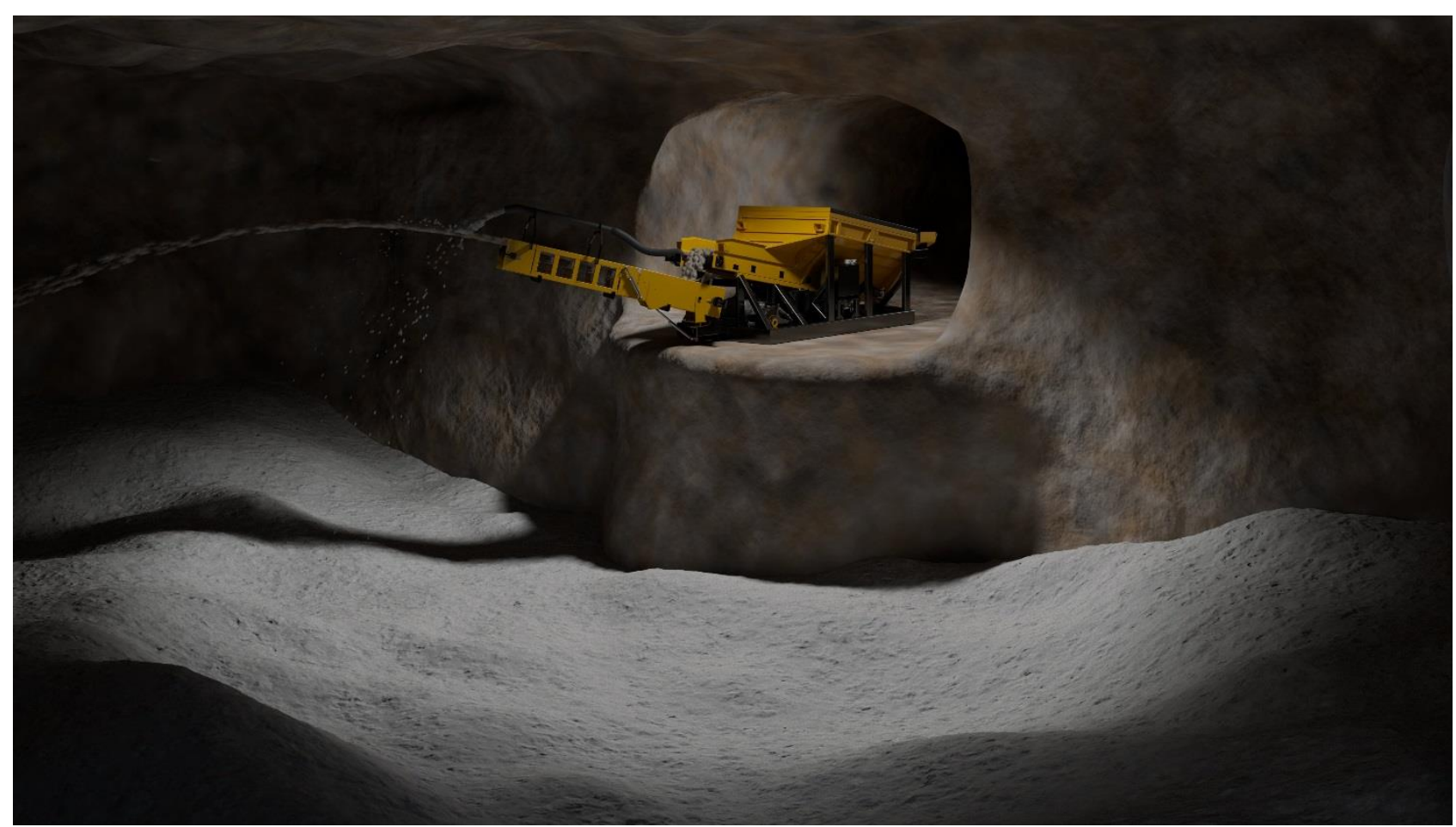

\section{Figure 4 Prototype co-disposal machine}

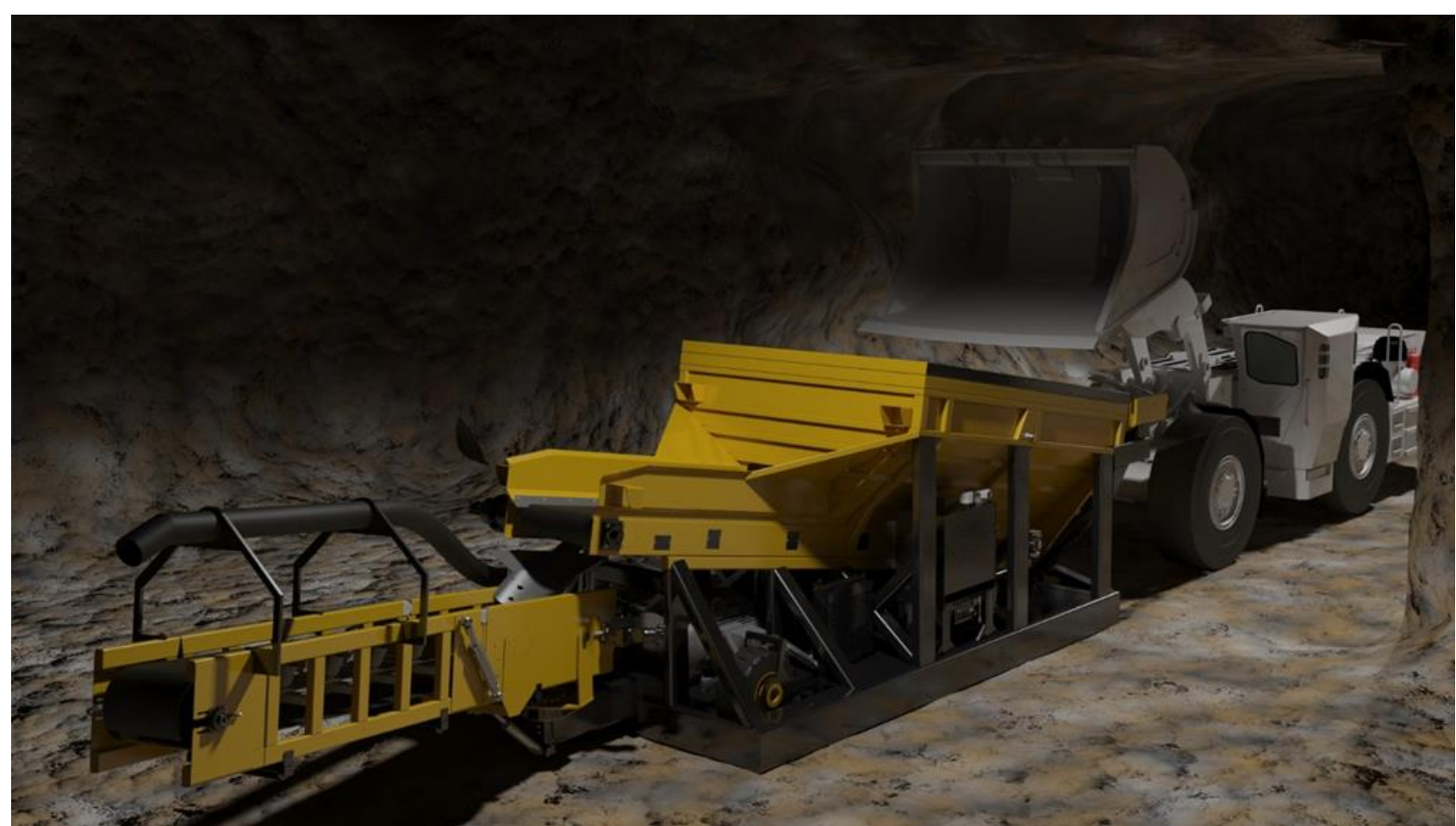

Figure 5 Prototype co-disposal machine 


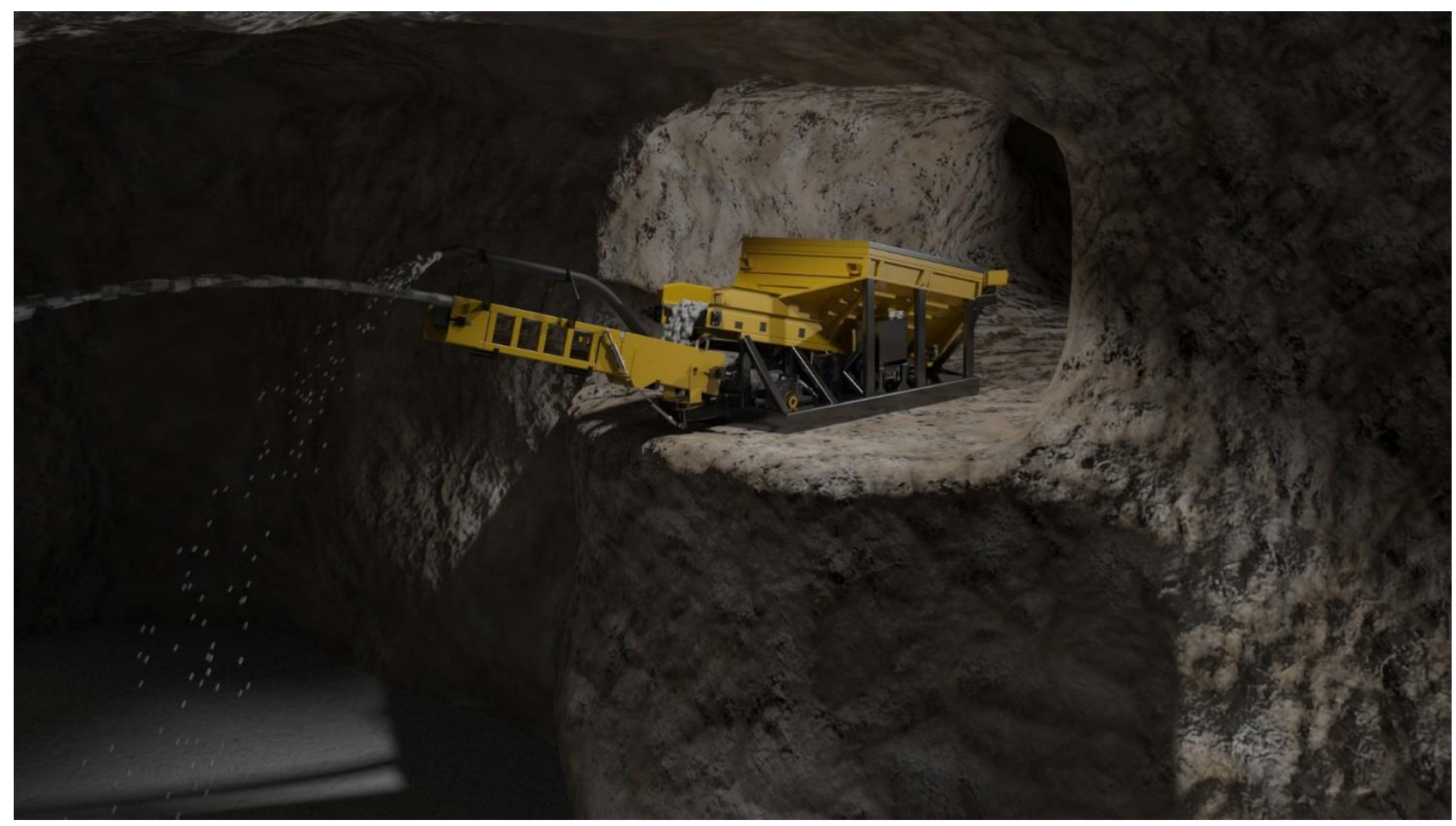

Figure 6 Prototype co-disposal machine

\section{Methods of operation}

The co-disposal machine would be towed to the top sill of an empty stope requiring fill. The machine has a set of trailer tyres and jacking mechanism that allows the tyres to project below the skid. When towed to the stope, the tyres would be retracted and the entire skid assembly would rest on the sill floor.

The skid has an integral paste discharge line which would be connected to a paste fill pipeline header using a flexible material handling hose

Waste rock would only be discharged into the stope during a paste pour. The paste pour would commence, and shortly after paste had entered the stope the waste rock co-disposal machine could be activated. When activated, a scoop would dump waste rock into the hopper which would meter the rock out onto the slinger conveyor. The slinger would accelerate the waste rock and fling it off of the end of the conveyor. Paste discharges at the slinger head end and would mix with the rock stream as it is projected out into the stope.

The slinger direction, tilt angle and speed will be controlled by the on-board control system so that rock is spread around the stope in a consistent pattern and no areas receive surges of waste rock. This widespread distribution of the waste rock will allow a much greater quantity of rock to be discharged into the stope compared to dumping scoop buckets over the brow of the stope.

Any oversize from the grizzly will be rehandled by a scoop to a secondary stope where the presence of large rocks is not a problem.

\subsection{Optimisations and modifications}

As the development of this concept proceeds, some optimisations have been envisaged:

- The design of a grizzly oversized handling system that would allow larger rocks to be discharged into the stope without entering the slinger is currently being evaluated. This would prevent the need for rehandling of oversized rocks into secondary stopes. This can be done and may require some changes in the grizzly geometry to ensure the gravity discharge of rocks from the grizzly. 
- The integration of safety fencing into the slinger so that it could be parked at the brow and the fences extended out to the walls of the drawpoint to prevent personnel approaching the brow of the stope would be a useful addition that would eliminate the requirement to erect fencing using loose materials such as mesh or snow fencing.

- The incorporation of a self-propelled carrier into the design is possible and is, in fact, a common feature in similar equipment produced by CAS. The cost of the self-propelled feature would need to be balanced against the utility of moving the machine around the mine without using any mobile equipment.

- The integration of the paste stream into the waste rock would be better if it was introduced at the tail end of the slinger. The reason that the paste pipe is currently located at the head end of the slinger is to minimise the amount of cemented paste build-up on the slinger itself. The downside of this arrangement is that the flow of paste reduces the velocity of the slung rock and the rock will need to be slung faster to reach the desired location. The ideal situation is that when rock is being discharged onto the slinger, the paste would be added at the tail end and when there is no rock on the slinger it would be added at the head end so that contact between the paste and the slinger is minimised. The paste pipe location could be controlled by the actuation of a hydraulic cylinder so that if waste rock was sensed on the belt, the discharge would be rotated to the tail end and vice versa. It should be noted that this slinger machine has been used to distribute concrete, so paste on the belt is not a problem, however, it is anticipated that it would require a higher degree of maintenance effort than if the paste never touched the belt.

\subsection{Alternative designs}

There are a number of different designs which have been considered that may prove more effective than the design currently envisaged or may be appropriate for different situations. Some of these designs include:

- Simplified design - although the rotating slinger head is ideal to maximise the even distribution of rock throughout the stope there are some mining methods or ore/waste ratios where it is not necessary to distribute the rock evenly. For example, for wide, deep stopes that will be mined transverse in a retreating sequence it may be possible to sling the rock to the back wall of the stope and fill a large amount of the stope with uncemented rock without exposing any of that uncemented rock to an exposed wall. An example of this is the filling of transverse stopes where backfill has already been placed on either side of the freshly excavated stope so that the only face of the stope that will be exposed is the front face. In this case, the slinger could simply be pointed to the back wall of the stope and used to sling uncemented rock while the paste is used to fill the remaining voids at the front of the stope. This would cut down on the cost and complexity of the slinger.

- The addition of rock directly by truck to the slinger is a potentially attractive option. Some modifications to the hopper would be required in order to receive a truck discharge, and it is likely that the slinger would be required to accommodate all sizes of rock which would limit its capability to sling the waste rock at high speeds. An ejector bed truck would likely be the best truck for this application so that the hopper size could be minimised due to the ability of the ejector bed to meter rock out of the back of the truck rather than dump it all at once. There are some geometry challenges with this option since the truck will need to be slightly higher than the hopper to dump properly and a small ramp at the drawpoint may be required. The benefit of this method is that no rehandling of waste rock by scoop from a truck dump location to the slinger would be required.

\section{Summary}

The co-disposal of waste rock with backfill has a cost advantage in many mines that have expensive waste rock haulage or expensive backfill. Depending on the cost of those two items and other, secondary costs, a waste rock co-disposal machine may be of benefit to the mine operation. 
The machine design presented in this paper could potentially fill the need for a co-disposal method that can achieve the desired benefits of co-disposal without the disadvantages typically seen in previous methods of co-disposal.

Currently, several mines are considering the trial of this co-disposal method and it is hoped that within a year a test case will be available in order to evaluate the potential for this technology.

\section{References}

Kuganathan, K \& Sheppard, I 2001, 'A non-segregating 'rocky paste fill' (RPF) produced by co-disposal of cemented de-slimed tailings slurry and graded rockfill', in D Stone (ed.), Proceedings of the Seventh International Symposium on Mining with Backfill, Society for Mining, Metallurgy and Exploration, Englewood, pp. 27-41. 